\title{
Dynamic interaction between a moving vehicle and an infinite structure excited by irregularities - Fourier transforms solution
}

\author{
J. Bitzenbauer, J. Dinkel
}

Summary A new approach to calculate the dynamic interaction between a moving vehicle and an infinite structure is presented. Its main characteristics are: use of Fourier transformed domains (leading to a very general formulation of the problem), correct consideration of the motion of all components of the model; consideration of all kinds of mutual dynamic interactions between the vehicle and the track, and the possibility to include a layered half-space for the subgrade, instead of the elastic Winkler foundation used here. Examples of a single axle and a bogie model passing an irregular track illustrate characteristic effects.

Keywords Track Dynamics, Dynamic Interaction, Rail, Irregularity, Slab-track System

1

Introduction

In this paper, we examine the dynamic behaviour of coupled infinite and continuous linear elastic beams in dynamic interaction with several moving linear multi-degree-of-freedom (MDOF) systems. Both cases of mutual dynamic interaction between the different contact points will be considered: the interaction via coupled degrees-of-freedom (DOF) of the moving structure, and the interaction via the substructure. All equations are held very general; in fact, the basic equations describe only an arbitrary number of moving contact points, regardless of the structures above or below.

The general formulation is motivated by the practical problem of a railway vehicle moving at constant speed on a track and being excited by given vertical imperfections such as flat wheels, rail irregularities and rail roughness. The resulting deflections of track and subgrade can be split into effects due to the moving dead load of the train and effects due to excitation caused by given vertical imperfections. The solution for the moving dead load is rather simple, whereas the semi-analytical solution of the interaction problem due to irregularities is the main issue of this paper.

This problem has already been treated by several authors. The first one to consider a moving load on an elastic track, was Timoshenko, [1, 2]; historically, papers [3-5] should be mentioned, too. A recent overview of vehicle-track dynamics is presented in [6]. Quite often the elasticity of the track is neglected, like in [7-11], or the vehicle is regarded to be at standstill. In this case, the roughness profile is pulled through the wheelset and the track to excite the

Received 13 December 1999; accepted for publication 21 September 2001

J. Bitzenbauer ( $₫)$

Institut für Mechanik, Universität Karlsruhe,

D-76131 Karlsruhe, Germany

e-mail: bitzenbauer@ifm.uni-karlsruhe.de

J. Dinkel

Lehrstuhl für Baumechanik,

Technische Universität München,

D-80290 München, Germany

e-mail: jens.dinkel@epost.de

The research reported here was done at the Lehrstuhl für Baumechanik, (TUM). The authors are greatly indebted to Harry Grundmann for his interest and advice. 
system, [12]. In [13], the problem is solved in the moving coordinate system, but the vehicle is partly fixed in vertical direction. Paper [14] presented a solution based on the approach given in [15] for a periodically supported rail modelled as a Timoshenko beam with a sinusoidal irregularity profile. This solution leads to a set of Fourier series for the vertical and angular displacements of the rail and the vertical displacements of the components of the vehicle. The coupling via the vehicle is not taken into account. The earliest approach to the dynamic interaction problem between vehicle and track which takes the speed of the vehicle and the elasticity of the track into account was presented in [16]. This semi-analytical approach for a continuous track model leads to a rather complicated expression for the receptance of the track in the frequency and Laplace domains. The receptance has to be evaluated using contour integration. Using this receptance and the receptance of a single wheelset, the contact force can be calculated.

In comparison to the semi-analytical solution strategies, different numerical models and methods have been developed by several authors who solve the problem correctly, e.g. [17-20]. For the dynamic interaction problem of a truck on a bridge, numerical techniques exist that could be adopted for the problem at hand of which only [21] and [22] should be mentioned here. Frýba's monographs $[23,24]$ focus on analytical solutions and extensively treat the subjects of moving loads and of vehicles on bridges. Moving oscillating loads are the subject of $[25,26]$.

The presented approach is a semi-analytical one which solves the problem in a correct manner, regarding the rail irregularities to be at a standstill and the railway vehicle to be in motion, [27]. Here, a continuous track model is used, representing a slab-track system better than a ballasted track, [28]. This approach leads to a closed form of the solution in Fourier domain different from the approaches [14] and [16]. The single expression clearly shows the influence of speed. The expression itself can be computed easily, and the inverse transforms can be performed numerically. In addition, the coupling via the vehicle will be derived using a bogie model.

Of course, a continuous model is a simplification of the track model appearing in reality, but, in consequence, closed-form analytical solutions using transformed domains are possible. With a continuous support, the pinned-pinned mode with a resonance frequency of around $1000 \mathrm{~Hz}$ cannot be taken into account. An advantage of the continuous model is the possibility to replace the Winkler foundation representing the subsoil with frequency- and wave numberdependent stiffness values of a three-dimensional layered half-space. The solution strategy presented can also be applied in this case.

As an example, a slab-track system described by two continuous layers of beams on elastic foundation (according to Fig. 1) is used, considering bending, shear, mass inertia and rotational inertia.

\section{2}

\section{Basic equations of the track in original domain}

In order to derive the differential equation describing an infinite and continuous beam on elastic foundation (taking into account bending, shear, mass inertia, rotational inertia and their interactions), an infinitesimal element and the corresponding forces, according to Fig. 2, are regarded. Symbols $M, Q$ and $p$ denote the bending moment, the shear force and the load; $w, w_{B}$ and $w_{Q}$ - the resulting deflection and its contributions due to bending and shear; $k$ and $c$ denote the stiffness coefficient and the damping coefficient of the elastic foundation,

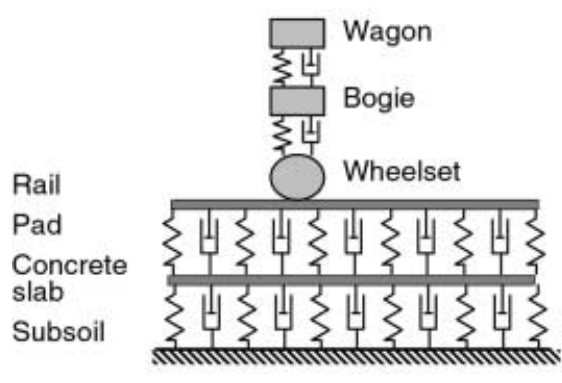

a

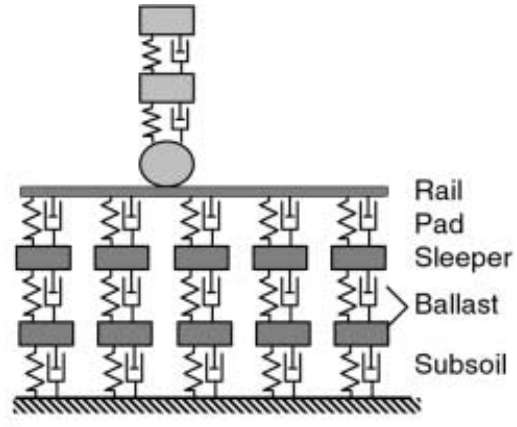

b

Fig. 1. One-dimensional track models with vehicle. Slab track system (a) and ballasted track (b) 


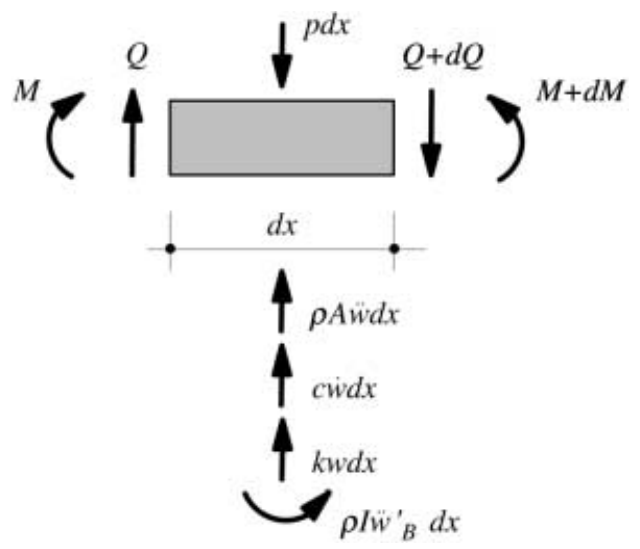

respectively; $\rho, E$ and $G A_{Q}$ are the mass density, Young's modulus and the shear stiffness, $A$ is the area of the cross section, and $I$ stands for the second moment of area. Symbols ()$=\partial / \partial t$ and $\left(^{\prime}\right)=\partial / \partial x$ denote the partial differentiations with respect to time and longitudinal direction. Using equations describing equilibrium, kinematics and linear elastic and homogeneous material law

$-Q(x, t)^{\prime}+\rho A \ddot{w}(x, t)+c \dot{w}(x, t)+k w(x, t)=p(x, t)$,

$Q(x, t)=M^{\prime}(x, t)+\rho I \ddot{w}_{B}^{\prime}(x, t)$,

$w(x, t)=w_{B}(x, t)+w_{Q}(x, t)$,

$M(x, t)=-E I w_{B}^{\prime \prime}(x, t)$,

$Q(x, t)=G A_{Q} w_{Q}^{\prime}(x, t)$,

the following differential equation holds:

$$
\begin{aligned}
& E I w^{\prime \prime \prime \prime}(x, t)-\rho I \ddot{w}^{\prime \prime}(x, t)+\rho A\left[\ddot{w}(x, t)-\frac{E I}{G A_{Q}} \ddot{w}^{\prime \prime}(x, t)+\frac{\rho I}{G A_{Q}} \dddot{w}(x, t)\right] \\
& \quad+c\left[\dot{w}(x, t)-\frac{E I}{G A_{Q}} \dot{w}^{\prime \prime}(x, t)+\frac{\rho I}{G A_{Q}} \dddot{w}(x, t)\right]+k\left[w(x, t)-\frac{E I}{G A_{Q}} w^{\prime \prime}(x, t)+\frac{\rho I}{G A_{Q}} \ddot{w}(x, t)\right] \\
& =p(x, t)-\frac{E I}{G A_{Q}} p^{\prime \prime}(x, t)+\frac{\rho I}{G A_{Q}} \ddot{p}(x, t) .
\end{aligned}
$$

3

\section{Basic equations in the Fourier-transformed domain}

3.1

\section{Equations for the track}

The equations for two coupled beams (see Fig. 1) follow from (6) by regarding the forces acting on the intermediate elastic foundation as the load on the lower beam. The resulting differential equations are transformed into the frequency $(\omega)$ and the wave-number domain $\left(k_{x}\right)$

$$
\begin{aligned}
& {\left[k_{x}^{4} E I_{1}-\kappa_{R 1}+\left(-\omega^{2} \rho A_{1}+\mathrm{i} \omega c_{\mathrm{p}}+k_{\mathrm{p}}\right)\left(1+\kappa_{Q 1}+\kappa_{Q R 1}\right)\right] w_{1}\left(k_{x}, \omega\right)} \\
& \quad-\left[\left(\mathrm{i} \omega c_{\mathrm{p}}+k_{\mathrm{p}}\right)\left(1+\kappa_{Q 1}+\kappa_{Q R 1}\right)\right] w_{2}\left(k_{x}, \omega\right) \\
& \quad=\left[1+\kappa_{Q 1}+\kappa_{Q R 1}\right] p\left(k_{x}, \omega\right) \\
& \quad\left[k_{x}^{4} E I_{2}-\kappa_{R 2}+\left(-\omega^{2} \rho A_{2}+\mathrm{i} \omega\left(c_{\mathrm{s}}+c_{\mathrm{p}}\right)+k_{\mathrm{s}}+k_{\mathrm{p}}\right)\left(1+\kappa_{Q 2}+\kappa_{Q R 2}\right)\right] w_{2}\left(k_{x}, \omega\right) \\
& \quad-\left[\left(\mathrm{i} \omega c_{\mathrm{p}}+k_{\mathrm{p}}\right)\left(1+\kappa_{Q 2}+\kappa_{Q R 2}\right)\right] w_{1}\left(k_{x}, \omega\right)=0 .
\end{aligned}
$$


Herein, the indices 1 and 2 denote the upper and the lower beam (the rail and the concrete slab) and the indices " $\mathrm{p}$ " and " $\mathrm{s"}$ " stand for pads and subgrade. Additional layers can be integrated easily, without changing the solution strategy presented in the next sections. The equation for one beam is just Eq. (7) without the $w_{2}$-term.

In the above expressions, the influences of shear $(Q)$, rotational inertia $(R)$ and the mutual action between shear and rotational inertia $(Q R)$ are represented via the factors

$\kappa_{Q 1 / 2}=k_{x}^{2} \frac{E I_{1 / 2}}{G A_{Q 1 / 2}}, \quad \kappa_{R 1 / 2}=k_{x}^{2} \omega^{2} \rho I_{1 / 2}, \quad \kappa_{Q R 1 / 2}=-\omega^{2} \frac{\rho I_{1 / 2}}{G A_{Q 1 / 2}}$.

Using (8), the following relation between $w_{1}\left(k_{x}, \omega\right)$ and $w_{2}\left(k_{x}, \omega\right)$ holds:

$w_{2}\left(k_{x}, \omega\right)=\kappa w_{1}\left(k_{x}, \omega\right)$,

with

$\kappa=\frac{\left(\mathrm{i} \omega c_{\mathrm{p}}+k_{\mathrm{p}}\right)\left(1+\kappa_{Q 2}+\kappa_{Q R 2}\right)}{k_{x}^{4} E I_{2}-\kappa_{R 2}+\left(-\omega^{2} \rho A_{2}+\mathrm{i} \omega\left(c_{\mathrm{s}}+c_{\mathrm{p}}\right)+k_{\mathrm{s}}+k_{\mathrm{p}}\right)\left(1+\kappa_{Q 2}+\kappa_{Q R 2}\right)}$.

In the transformed domain, the relations between the load $p\left(k_{x}, \omega\right)$ and the deflections $w_{1}\left(k_{x}, \omega\right)$ and $w_{2}\left(k_{x}, \omega\right)$ are

$w_{1}\left(k_{x}, \omega\right)=\frac{p\left(k_{x}, \omega\right)}{D_{1}\left(k_{x}, \omega\right)}, \quad w_{2}\left(k_{x}, \omega\right)=\frac{p\left(k_{x}, \omega\right)}{D_{2}\left(k_{x}, \omega\right)} ，$

using the transformed differential operators

$$
\begin{aligned}
& D_{1}\left(k_{x}, \omega\right)=\frac{k_{x}^{4} E I_{1}-\kappa_{R 1}}{1+\kappa_{Q 1}+\kappa_{Q R 1}}-\omega^{2} \rho A_{1}+\left(\mathrm{i} \omega c_{\mathrm{p}}+k_{\mathrm{p}}\right)(1-\kappa), \\
& D_{2}\left(k_{x}, \omega\right)=\frac{D_{1}\left(k_{x}, \omega\right)}{\kappa} .
\end{aligned}
$$

The first advantage of this approach is the simple description of the shear, the rotation and the interaction between shear and rotation in the transformed domain. If wanted, these influences can be neglected by setting the corresponding $\kappa$-terms in Eqs. (9) equal to zero.

The second advantage of the description in the transformed domain is the possibility to include a layered half-space as a model for the subgrade. This leads to the frequency- and wave-number-dependent spring and damper coefficients, instead of constant parameters for the elastic support. In this case, $k_{\mathrm{s}}$ and $c_{\mathrm{s}}$ are replaced in Eq. (8) by the half-space stiffnesses $k_{\mathrm{H}}\left(k_{x}, \omega\right)=k_{\mathrm{H}}^{R}\left(k_{x}, \omega\right)+\mathrm{i} k_{\mathrm{H}}^{I}\left(k_{x}, \omega\right)$, derived from the fundamental solution in the transformed domain of the half-space under harmonic loading. These stiffnesses describe the properties of the layered half-space in a correct manner. The concept was developed and presented in [29], and is extensively examined in [30]. A similar formulation can be found in [31].

\section{2}

\section{Equations for the vehicle}

\subsection{1}

\section{MDOF systems with one contact point}

For nonbranched structures, like the one with three DOF shown in Fig. 3a, the relation in the frequency domain between vertical wheel displacement $w_{\mathrm{w}}(\omega)$ and normal force $N(\omega)$ is

$N(\omega)=k_{\mathrm{w}}(\omega) w_{\mathrm{w}}(\omega)$,

wherein $k_{\mathrm{w}}(\omega)$ can be gained using the impedance relations 

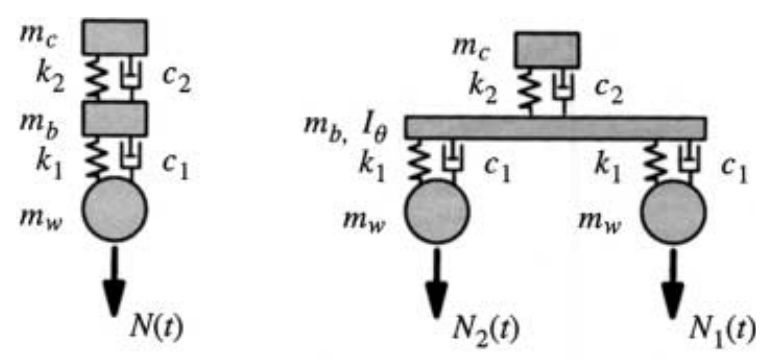

a

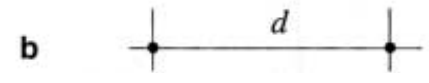

Fig. 3. Vehicle models with one contact point (a) or more than one-bogie model (b)

$k_{\mathrm{c}}(\omega)=-\omega^{2} m_{\mathrm{c}}$,

$k_{\mathrm{s}}(\omega)=\frac{1}{\frac{1}{k_{\mathrm{c}}(\omega)}+\frac{1}{i \omega c_{2}+k_{2}}}-\omega^{2} m_{\mathrm{b}}$

$k_{\mathrm{w}}(\omega)=\frac{1}{\frac{1}{k_{\mathrm{s}}(\omega)}+\frac{1}{i \omega c_{1}+k_{1}}}-\omega^{2} m_{\mathrm{w}}$.

In (16) to (18), $m_{\mathrm{c}}, m_{\mathrm{b}}$ and $m_{\mathrm{w}}$ denote the mass of the car body, the bogie and the wheelset, while stiffness and damping coefficients of the primary and secondary spring and damper elements are denoted by $k_{1 / 2}$ and $c_{1 / 2}$, respectively.

\subsection{2}

\section{MDOF systems with several contact points}

Equations for a bogie model with five DOF and two contact points with the corresponding normal forces $N_{1 / 2}$ (see Fig. 3b) are taken from [17] in a slightly modified manner, and transformed into frequency domain

$\mathbf{K}(\omega) \mathbf{w}(\omega)=\mathbf{p}(\omega)$,

which can be written in detail as

$$
\begin{aligned}
& {\left[\begin{array}{ccccc}
-\omega^{2} m_{\mathrm{c}}+\mathrm{i} \omega c_{2}+k_{2} & -\mathrm{i} \omega c_{2}-k_{2} & 0 & 0 & 0 \\
& -\omega^{2} m_{\mathrm{b}}+\mathrm{i} \omega\left(2 c_{1}+c_{2}\right)+2 k_{1}+k_{2} & 0 & -\mathrm{i} \omega c_{1}-k_{1} & -\mathrm{i} \omega c_{1}-k_{1} \\
& -\omega^{2} I_{\theta}+2 d^{2}\left(\mathrm{i} \omega c_{1}+k_{1}\right) & \mathrm{i} \omega d c_{1}+d k_{1} & -\mathrm{i} \omega d c_{1}-d k_{1} \\
& & & -\omega^{2} m_{\mathrm{w}}+\mathrm{i} \omega c_{1}+k_{1} & 0 \\
& & & & -\omega^{2} m_{\mathrm{w}}+\mathrm{i} \omega c_{1}+k_{1}
\end{array}\right]} \\
& \times\left[\begin{array}{c}
w_{\mathrm{c}}(\omega) \\
w_{\mathrm{b}}(\omega) \\
\phi_{\mathrm{b}}(\omega) \\
w_{\mathrm{w1}}(\omega) \\
w_{\mathrm{w} 2}(\omega)
\end{array}\right]=\left[\begin{array}{c}
0 \\
0 \\
0 \\
N_{1}(\omega) \\
N_{2}(\omega)
\end{array}\right]
\end{aligned}
$$

Here, $\phi_{\mathrm{b}}(\omega)$ and $I_{\theta}$ denote rotation and rotational inertia of the bogie, all other symbols are according to the previous section.

\section{4}

\section{Solution for the moving dead load}

A detailed description of the solution for the vertical displacements of the track for one and for four moving dead loads and its effects without any influences of shear and rotation can be found in [26]. In our context, we regard the more general case of $n$ moving dead loads $G$. The first load is placed at the origin in the $x$-domain, the $i$-th load stands at $x_{i}=-l_{i}$

$p(x, t)=G \sum_{i=1}^{n} \delta\left(x-v t+l_{i}\right), \quad p\left(k_{x}, \omega\right)=2 \pi G \sum_{i=1}^{n} \mathrm{e}^{\mathrm{i} l_{i} k_{x}} \delta\left(\omega+v k_{x}\right)$. 
After using (12) and performing the Inverse Fourier Transform, the deflections become

$w_{1 / 2}(x, t)=\frac{G}{2 \pi} \sum_{i=1}^{n} \int_{-\infty}^{+\infty} \frac{\mathrm{e}^{\mathrm{i}\left(x-v t+l_{i}\right) k_{x}}}{D_{1 / 2}\left(k_{x}, \omega=-v k_{x}\right)} \mathrm{d} k_{x}$.

Due to the moving dead load, no displacements occur in the vehicle since the vertical position of each wheelset is constant while moving.

\section{5}

\section{Vertical displacements and contact restrictions}

In the previous section, the elastic and dynamic behaviour of the moving railway vehicle did not matter. This is no longer the fact in the case when imperfections cause a dynamic excitation. In general, imperfections are the differences between the ideal and the real position of the rail or between the ideal and the real form of the wheels. In this paper, only vertical imperfections will be considered.

In this context, a simplified approach for semi-analytical solutions of exciting the train-track system is to regard train and track to be at a standstill and to pull through the irregularities against the moving direction of the train. But, in reality, the track and, therefore, rail irregularities and rail roughness are in fixed position and the train is moving. In case of flat wheels, the out-of-rounds are passing the fixed track. The aim of our approach is to consider the real state of motion of all components (compare Fig. 4).

Assuming a permanent point contact between the rail and all wheelsets at the moving contact points, the contact restriction

$w_{\mathrm{w}}(t)=\Delta w(t)+w_{1}(x=v t, t)$,

can be given. In (23), $w_{\mathrm{w}}$ and $w_{1}$ are the vertical displacements of the wheelset and the rail at the moving contact points and $\Delta w(t)=\Delta w(x / v)$ is the given irregularity.

\section{6}

\section{One moving contact point}

The solution strategy and the basic solution will be shown for one moving contact point with a simple nonbranched structure above, since the transfer to branched structures with several moving contact points can be done easily. The equation

$p(x, t)=-\delta(x-v t) N(t)$,

and its Fourier-transformed counterpart

$p\left(k_{x}, \omega\right)=-\delta\left(\omega+v k_{x}\right) * N(\omega)=-N\left(\omega+v k_{x}\right)=-k_{\mathrm{w}}\left(\omega+v k_{x}\right) w_{\mathrm{w}}\left(\omega+v k_{x}\right)$,

describes the normal force between vehicle and track as a load moving at speed $v$ on the substructure; herein $(*)$ denotes a convolution. Equation (15) is used to express the normal force in an alternative manner. Using (25) and (12), the deflection of the rail in the transformed domain is

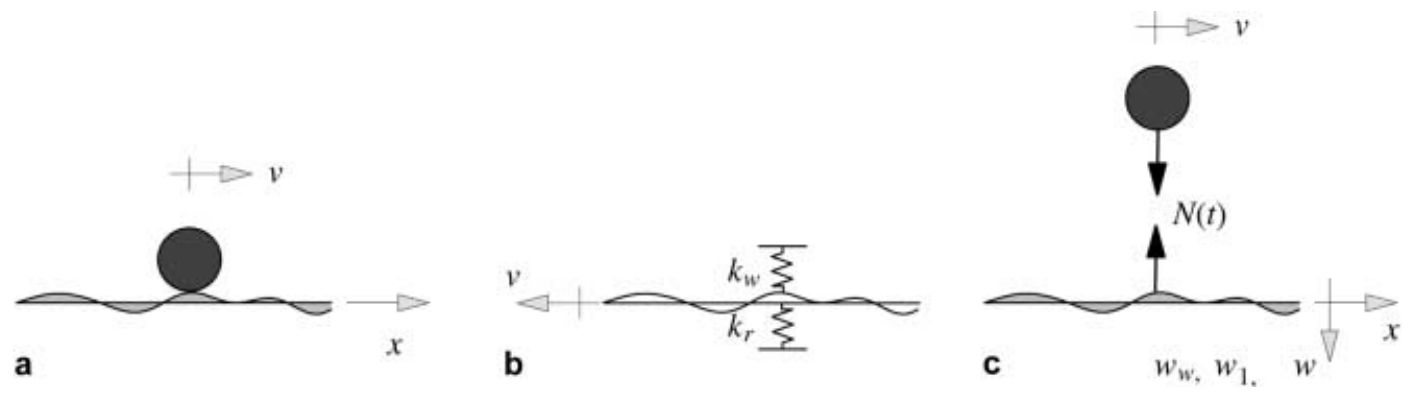

Fig. 4. Problem (a), common approach to the problem (b), presented approach (c) 
$w_{1}\left(k_{x}, \omega\right)=\frac{p\left(k_{x}, \omega\right)}{D_{1}\left(k_{x}, \omega\right)}=-\frac{k_{\mathrm{w}}\left(\omega+v k_{x}\right) w_{\mathrm{w}}\left(\omega+v k_{x}\right)}{D_{1}\left(k_{x}, \omega\right)}$.

The contact restriction (23) can be written as

$\frac{1}{4 \pi^{2}} \iint_{-\infty}^{+\infty} w_{1}\left(k_{x}, \omega\right) \mathrm{e}^{\mathrm{i} k_{x} v t} \mathrm{e}^{\mathrm{i} \omega t} \mathrm{~d} k_{x} \mathrm{~d} \omega=w_{\mathrm{w}}(t)-\Delta w(t)$

using the inverse transform at $x=v t$. Multiplying both sides of Eq. (27) with $\mathrm{e}^{-\mathrm{i} \Omega t}$, and performing an integration from $-\infty$ to $+\infty$ (actually a new Fourier Transform into a frequency domain $\Omega$ ), we get after rearranging

$\frac{1}{4 \pi^{2}} \iint_{-\infty}^{+\infty} w_{1}\left(k_{x}, \omega\right)\left[\int_{-\infty}^{+\infty} 1 \cdot \mathrm{e}^{-\mathrm{i}\left(\Omega-\omega-v k_{x}\right) t} \mathrm{~d} t\right] \mathrm{d} k_{x} \mathrm{~d} \omega=w_{\mathrm{w}}(\Omega)-\Delta w(\Omega)$.

The inner integral corresponds to a Fourier Transform of the constant function 1 into a domain using the transformation kernel $\Omega-\omega-v k_{x}$. The transform leads to

$\frac{1}{2 \pi} \iint_{-\infty}^{+\infty} w_{1}\left(k_{x}, \omega\right) \delta\left(\Omega-\omega-v k_{x}\right) \mathrm{d} k_{x} \mathrm{~d} \omega=w_{\mathrm{w}}(\Omega)-\Delta w(\Omega)$

Considering the properties of the Dirac distribution and relation (26) with the argument $\omega=\Omega-v k_{x}$

$w_{1}\left(k_{x}, \omega=\Omega-v k_{x}\right)=-\frac{k_{\mathrm{w}}(\Omega) w_{\mathrm{w}}(\Omega)}{D_{1}\left(k_{x}, \omega=\Omega-v k_{x}\right)}$,

we get

$-\frac{k_{\mathrm{w}}(\Omega) w_{\mathrm{w}}(\Omega)}{2 \pi} \int_{-\infty}^{+\infty} \frac{\mathrm{d} k_{x}}{D_{1}\left(k_{x}, \omega=\Omega-v k_{x}\right)}=w_{\mathrm{w}}(\Omega)-\Delta w(\Omega)$

where $k_{\mathrm{w}}(\Omega)$ and $w_{\mathrm{w}}(\Omega)$ can be put outside the integral, for they no longer depend on $k_{x}$ but rather on $\Omega$. Solving the equation leads to the unknown transformed vertical wheel displacement

$w_{\mathrm{w}}(\Omega)=\frac{2 \pi \Delta w(\Omega)}{2 \pi+k_{\mathrm{w}}(\Omega) \alpha(\Omega, v)}$,

with

$\alpha(\Omega, v)=\int_{-\infty}^{+\infty} \frac{\mathrm{d} k_{x}}{D_{1}\left(k_{x}, \omega=\Omega-v k_{x}\right)}$

and, using (26), we get the unknown transformed vertical displacement of the rail. The term $\alpha(\Omega, v)$ defines the receptance (as a complex quantity) of the rail in the moving coordinate system.

One, respectively, two Inverse Fourier Transforms (to be performed numerically) lead to the vertical displacements of the wheel and rail in the original domain. The complete vertical displacements can be obtained by superposition with the vertical displacements due to the moving dead load. 


\section{7}

\section{Several moving contact points}

In this section, we extend the method to an arbitrary number of contact points which can also be coupled via the vehicle. With this approach, the dynamic interaction takes place via the track and the vehicle itself. It is sufficient to regard one vehicle because the solution for more vehicles is given implicitly. In general, the vehicle has $n$ DOF, $m$ of which are in contact with the rail. At these $m$ contact points, we have $m$ contact forces $N_{i}(\Omega)$ with $i=1, \ldots, m$. There are $r=n-m$ DOF not in contact with the rail. In the following, the indices denote the dimensions of the matrices and vectors. The equation

$\mathbf{K}_{n \times n}(\Omega) \mathbf{w}_{n}(\Omega)=\left[\begin{array}{c}\mathbf{0}_{r} \\ \mathbf{N}_{m}(\Omega)\end{array}\right]$,

describes the behaviour of the $n$ DOF of the moving vehicle in dependence of the $m$ contact forces. Herein, $\mathbf{K}_{n \times n}(\Omega)$ is the stiffness matrix coupling the $n$ DOF with each other. The vector $\mathbf{w}_{n}(\Omega)$ contains all displacements of the vehicle, $\mathbf{N}_{m}(\boldsymbol{\Omega})$ contains the contact forces and $\mathbf{0}_{r}$ denotes a zero vector of dimension $r$. The contact forces are unknown, but the linear equations (34) can be reduced to linear equations

$\mathbf{K}_{m \times m}^{*}(\Omega) \mathbf{w}_{m}(\Omega)=\mathbf{N}_{m}(\Omega) \Leftrightarrow \mathbf{K}_{m \times m}^{*}(\Omega)^{-1} \mathbf{N}_{m}(\Omega)=\mathbf{w}_{m}(\Omega)$,

in which only the DOF belonging to contact points occur. Besides (35), we have $m$ additional equations resulting from fulfilling the $m$ contact restrictions

$w_{1}\left(x=v t-l_{i}, t\right)=w_{w, i}(t)-\Delta w\left(t-l_{i} / v\right) \quad \forall i=1, \ldots, m$,

which by means of

$w_{1}\left(k_{x}, \Omega\right)=-\frac{\sum_{j=1}^{m} \mathrm{e}^{\mathrm{i} k_{x} l_{j}} N_{j}(\Omega)}{D_{1}\left(k_{x}, \omega=\Omega-v k_{x}\right)}$,

can be transformed to

$w_{w, i}(\Omega)+\frac{1}{2 \pi} \sum_{j=1}^{m} N_{j}(\Omega) \int_{-\infty}^{+\infty} \frac{\mathrm{e}^{\mathrm{i} k_{x}\left(l_{j}-l_{i}\right)}}{D_{1}\left(k_{x}, \omega=\Omega-v k_{x}\right)} \mathrm{d} k_{x}=\mathrm{e}^{-\frac{\mathrm{i} \Omega l_{i}}{v}} \Delta w(\Omega)$.

Finally, (35) and (38) together lead to

$\left[\mathbf{K}_{m \times m}^{*}(\Omega)^{-1}+\mathbf{A}_{m \times m}(\Omega)\right] \mathbf{N}_{m}(\Omega)=\mathbf{b}_{m}(\Omega) \Delta w(\Omega)$,

using

$A_{i j}(\Omega)=\frac{1}{2 \pi} \int_{-\infty}^{+\infty} \frac{\mathrm{e}^{\mathrm{i}\left(l_{j}-l_{i}\right) k_{x}}}{D_{1}\left(k_{x}, \omega=\Omega-v k_{x}\right)} \mathrm{d} k_{x} \quad \forall i, j=1, \ldots, m$,

$b_{i}(\Omega)=\mathrm{e}^{-\frac{i \Omega l_{i}}{v}} \forall i=1, \ldots, m$.

Herein, the matrix $\mathbf{A}_{m \times m}(\Omega)$ describes the track and $\mathbf{K}_{m \times m}^{*}(\Omega)^{-1}$ describes the vehicle. By solving the linear system (40) for several frequencies, the normal forces in the transformed domain can be obtained. The use of (37) leads to the transformed deflections of the track.

If one either wants to avoid the inversion of $\mathbf{K}_{m \times m}^{*}(\Omega)$ or prefers to calculate $\mathbf{w}_{m}(\Omega)$ rather than $\mathbf{N}_{m}(\Omega)$, the following equation holds:

$\left[\mathbf{I}_{m \times m}+\mathbf{A}_{m \times m}(\Omega) \mathbf{K}_{m \times m}^{*}(\Omega)\right] \mathbf{w}_{m}(\Omega)=\mathbf{b}_{m}(\Omega) \Delta w(\Omega)$,

with the unit matrix $\mathbf{I}_{m \times m}$. 


\section{Examples}

In Fig. 5, the amplitudes of the complex receptances for different velocities and different damping parameters are shown. Parameters according to Table 1 were used for calculation of the left hand side figure. In the graphs, Fig. $5 b-c$, the damping of the intermediate layer is increased by a factor 10 and 100, respectively. The first peak can be assigned to a resonance effect of the lower beam (plate), and the second one belongs to the upper beam (rail). It can easily be seen that in some low frequency ranges the receptance does depend on the velocity. Significant differences only occur at resonance frequencies and in the case of supercritical damping (Fig. 5c) in the low frequency range. Some aspects of Eqs. (12) and (13) should be looked at in more detail here. Note that the most simplified model, a simply supported beam, can be discussed by setting all $\kappa$-terms equal to zero. The effect of speed in Eqs. (12) and (13)

$w\left(k_{x}, \Omega\right)=p\left(k_{x}, \Omega\right) \frac{E I k_{x}^{4}-\mu\left(\Omega-v k_{x}\right)^{2}-\mathrm{i} c\left(\Omega-v k_{x}\right)+k}{\left(E I k_{x}^{4}-\mu\left(\Omega-v k_{x}\right)^{2}+k\right)^{2}+c^{2}\left(\Omega-v k_{x}\right)^{2}}$,

does not lead to deflections with unbounded growth. In the particular solution, a positive sign of the terms describing damping $\left(v k_{x}>\Omega\right)$ does not affect the amplitudes but only the phases. In the homogeneous solution (which is not needed here), no term depending on the velocity exists. For the case $\Omega=0$ (i.e. moving dead load), two different types of behaviour can be regarded: for low damping, in the subcritical range $0<v<v_{\text {crit }}$ with increasing speed the deflections must increase, too, since the denominator of (43) becomes smaller, whereas for sufficiently high damping and increasing speed the deflections must decrease. This tendency is very similar for low frequencies, whereas for $\Omega \gg v k_{x}$ the influence of speed becomes negligible, in general, since then due to the quadratic expressions in the denominator the $v^{2} k_{x}^{2}$ terms become small in comparison with the $\Omega^{2}$ terms.
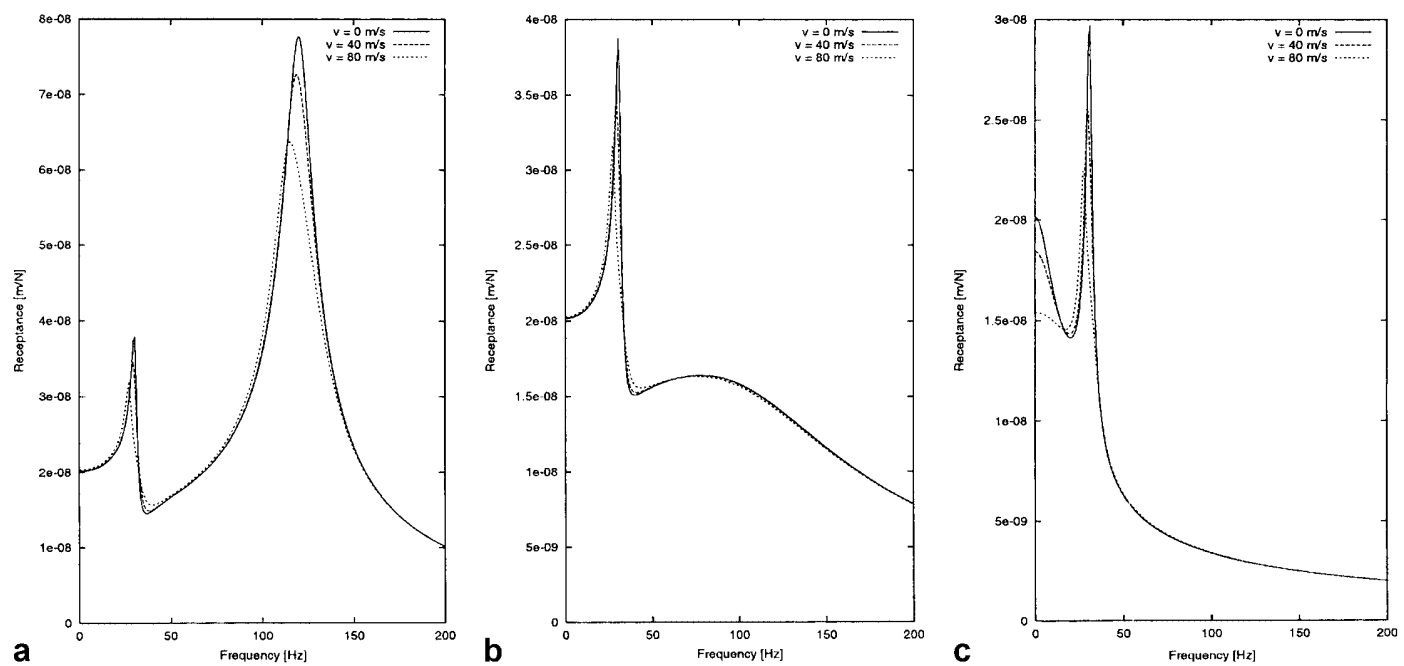

Fig. 5. Amplitude of receptance of the upper beam of a system of two coupled beams. Variation of damping and velocity versus frequency. (a) low damping (parameters according to Table 1), (b) medium damping (factor 10), (c) high damping (factor 100)

Table 1. Parameters of the slab track system (half)

\begin{tabular}{llll}
\hline$E_{1}$ & $2.10 \cdot 10^{11} \mathrm{~N} / \mathrm{m}^{2}$ & $E_{2}$ & $3.00 \cdot 10^{10} \mathrm{~N} / \mathrm{m}^{2}$ \\
$G A_{Q 1}$ & $2.62 \cdot 10^{8} \mathrm{~N}$ & $G A_{Q 2}$ & $7.29 \cdot 10^{9} \mathrm{~N}$ \\
$\rho_{1}$ & $7800 \mathrm{~kg} / \mathrm{m}^{3}$ & $\rho_{2}$ & $2400 \mathrm{~kg} / \mathrm{m}^{3}$ \\
$A_{1}$ & $7.69 \cdot 10^{-3} \mathrm{~m}^{2}$ & $A_{2}$ & $0.70 \mathrm{~m}^{2}$ \\
$I_{1}$ & $3.05 \cdot 10^{-5} \mathrm{~m}^{4}$ & $I_{2}$ & $9.33 \cdot 10^{-3} \mathrm{~m}^{4}$ \\
$k_{\mathrm{p}}$ & $3.3 \cdot 10^{7} \mathrm{~N} / \mathrm{m}^{2}$ & $k_{\mathrm{s}}$ & $6.6 \cdot 10^{7} \mathrm{~N} / \mathrm{m}^{2}$ \\
$c_{\mathrm{p}}$ & $5.0 \cdot 10^{3} \mathrm{~N} \mathrm{~s} / \mathrm{m}^{2}$ & $c_{\mathrm{s}}$ & $3.0 \cdot 10^{4} \mathrm{~N} \mathrm{~s} / \mathrm{m}^{2}$ \\
\hline
\end{tabular}



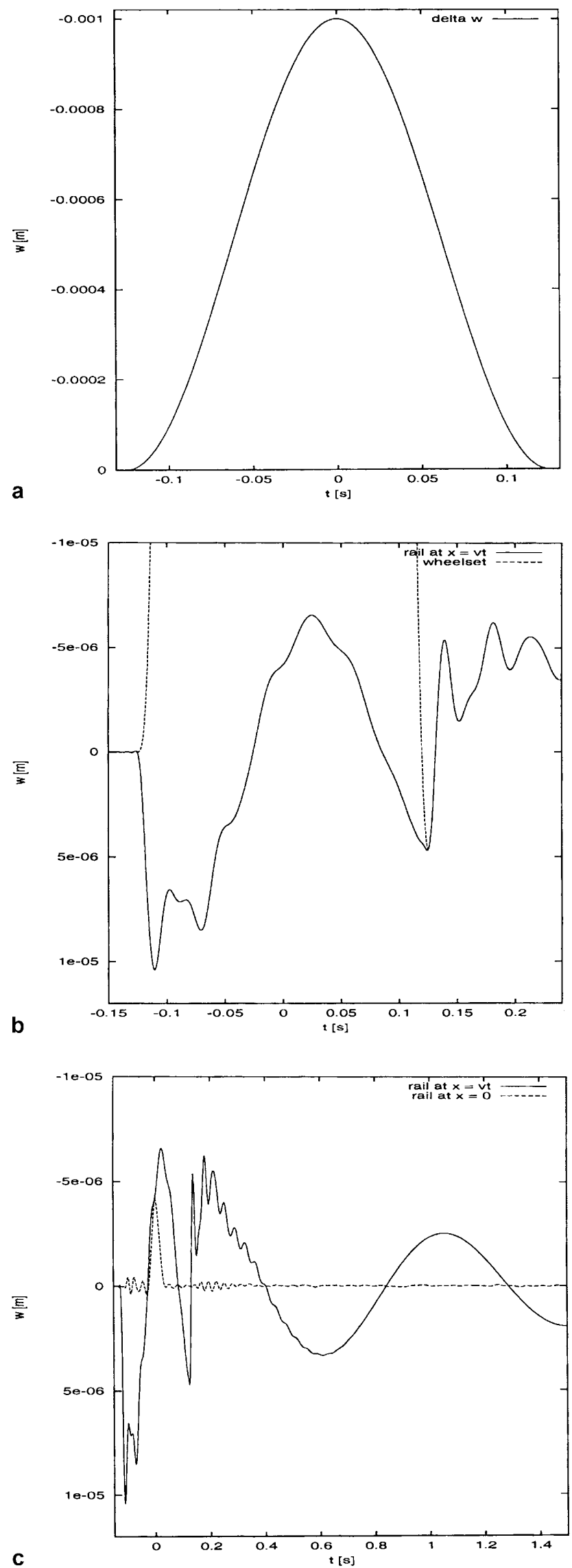

Fig. 6. Given rail irregularity, cosine form (a); vertical displacements of wheelset and rail at the contact point (b), figure is cut to show the fulfillment of the contact restriction at $t= \pm 0.125 \mathrm{~s}$; deflections of the rail at $x=v t$ and at $x=0(\mathrm{c})$ 
Some serious limitations of the underground model used here should be mentioned: the use of a winkler foundation instead of the half-space, and the unrealistic assumption of frequencyproportional viscous damping. It can be seen that a change in the damping parameters of the intermediate layer changes the behaviour of the system strongly. Of course, this holds similarly for changing the damping parameters or even the whole mechanical model of the subsoil. Indeed, calculations of the second author, using a half-space model with hysteretic damping, indicate that, in reality, the first peak does not exist in the way shown here, and that there is also less dependence on velocity.

The second example (Fig. 6) shows a single three DOF model (parameters according to Table 2) moving at a speed of $v=80 \mathrm{~m} / \mathrm{s}$ and being excited by the rail irregularity given in Fig. 6a. Figure $6 \mathrm{~b}$ shows the responses of the wheelset and rail at the moving contact point $x=v t$. As track and subgrade in the low frequency range are, generally, much stiffer than the vehicle, the deflections of the rail are quite small. At $t= \pm 0.125 \mathrm{~s}$, the wheel reaches the beginning (the end, respectively) of the irregularity and one can observe that the contact restriction is fulfilled. Regarding the deflections of the rail at the moving contact point and the ones at the fixed point $x=0$ (Fig. $6 \mathrm{c}$ ), the identity of the deflections at the moment the train passes the fixed point is obvious.

Table 2. Parameters of the three-DOF vehicle ( $1 / 8$ of a wagon)

\begin{tabular}{lrll}
\hline$m_{\mathrm{w}}$ & $880 \mathrm{~kg}$ & $k_{1}$ & $9.72 \cdot 10^{5} \mathrm{~N} / \mathrm{m}$ \\
$m_{\mathrm{b}}$ & $745 \mathrm{~kg}$ & $c_{1}$ & $1.2 \cdot 10^{4} \mathrm{~N} \mathrm{~s} / \mathrm{m}$ \\
$m_{\mathrm{c}}$ & $5075 \mathrm{~kg}$ & $k_{2}$ & $3.52 \cdot 10^{5} \mathrm{~N} / \mathrm{m}$ \\
& & $c_{2}$ & $1.0 \cdot 10^{4} \mathrm{~N} \mathrm{~s} / \mathrm{m}$ \\
\hline
\end{tabular}
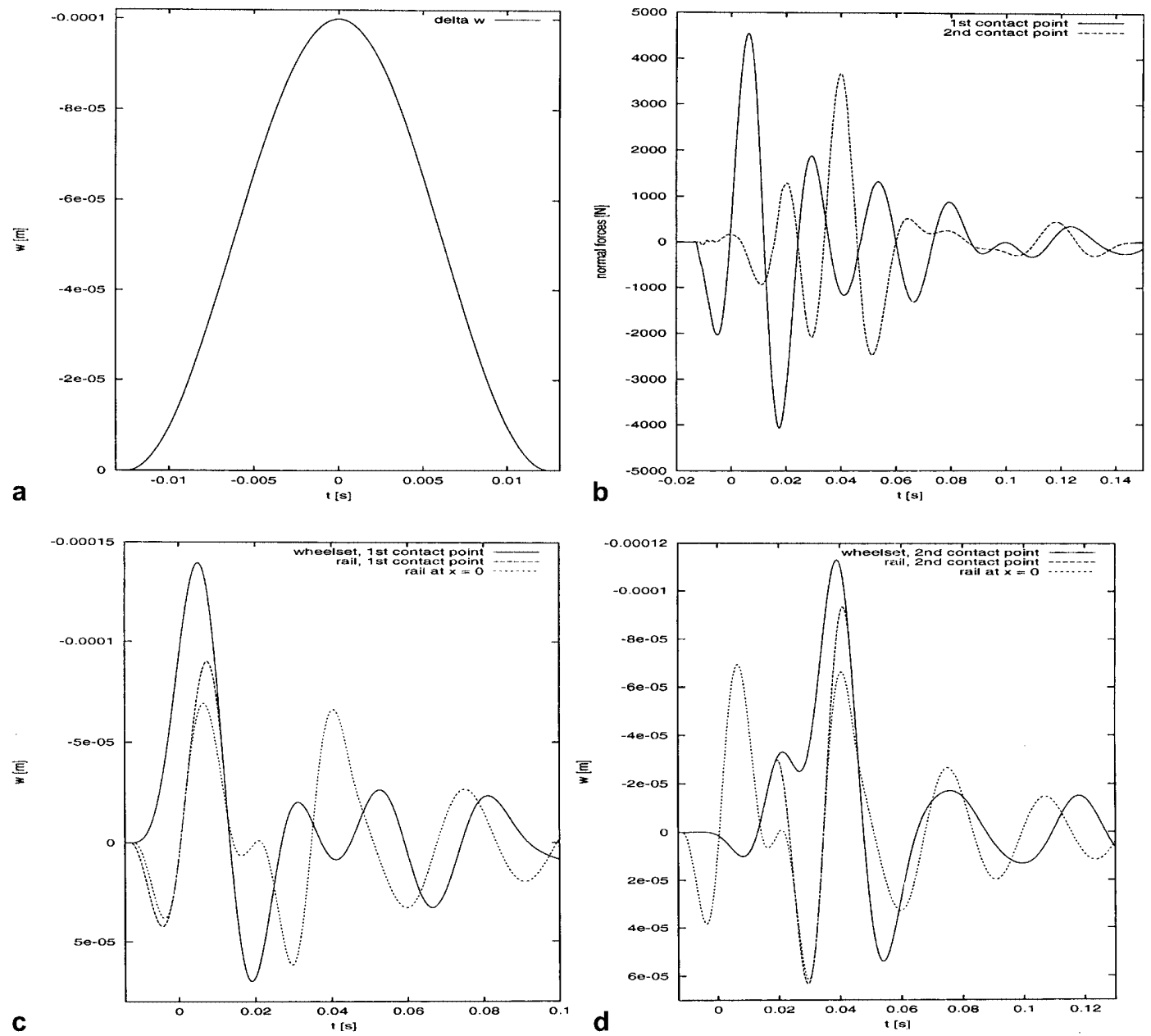

Fig. 7. Given rail irregularity, cosine form (a); dynamic normal forces at the contact points (b); vertical displacements of wheelset and rail at first (c) and second (d) contact point 
Table 3. Parameters of the five-DOF bogie (1/4 of a wagon)

\begin{tabular}{llll}
\hline$m_{\mathrm{w}}$ & $880 \mathrm{~kg}$ & $k_{1}$ & $9.72 \cdot 10^{5} \mathrm{~N} / \mathrm{m}$ \\
$m_{\mathrm{b}}$ & $1490 \mathrm{~kg}$ & $c_{1}$ & $1.2 \cdot 10^{4} \mathrm{~N} \mathrm{~s} / \mathrm{m}$ \\
$m_{\mathrm{c}}$ & $10150 \mathrm{~kg}$ & $k_{2}$ & $7.04 \cdot 10^{5} \mathrm{~N} / \mathrm{m}$ \\
$I_{\theta}$ & $1600 \mathrm{~kg} \mathrm{~m}$ & $c_{2}$ & $2.0 \cdot 10^{4} \mathrm{~N} \mathrm{~s} / \mathrm{m}$ \\
$d$ & $2.50 \mathrm{~m}$ & & \\
\hline
\end{tabular}

The third example (Fig. 7) shows the results for a single bogie model with five DOF (parameters according to Table 3 ) being excited by the same cosine form rail irregularity. The speed again is $v=80 \mathrm{~m} / \mathrm{s}$, the distance between the wheelsets of the bogie is $2.50 \mathrm{~m}$. In this example, much higher frequencies than in the previous one are excited. Therefore, the stiffness of the vehicle increases and, subsequently, there is a notable interaction between the wheelsets. This can easily be seen when regarding the normal forces (Fig. $7 \mathrm{~b}$ ); although the second wheelset reaches the beginning of the imperfection at $t=+0.01875 \mathrm{~s}$, there occur nonzero dynamic normal forces before that time. Of course, the main part of the mutual interaction between the wheelsets of one bogie is the interaction through the bogie. Normal forces below zero do not indicate a take off since the moving dead load is much higher than the dynamic normal forces. The graphs Fig. $7 \mathrm{c}-\mathrm{d}$ show again the fulfillment of the contact restrictions, the deflections at the fixed point and the mutual interaction between the wheelsets.

\section{9}

\section{Conclusion}

A new semi-analytical approach for the calculation of the dynamic interaction between vehicle and track for a continuous model leading to a closed-form solution in the Fourier domain has been presented. The developed method considers the influence of the state of motion of all components of the model. In practice, the mutual interaction between the wheelsets via track and subgrade increases for higher frequencies. This aspect is included in the solution, too. It should be mentioned that, for higher frequencies, a contact spring between wheelset and rail should be included, see e.g. [16]. In order to calculate other subgrade models, only the differential operator needs to be changed. Worth mentioning is the possibility to include a halfspace instead of the Winkler foundation used here, as shown in [30].

Our intention was to propose a new approach to the calculation of the dynamic interaction problem between a moving vehicle and a substructure and to show that under certain circumstances the receptance might depend on the velocity, too. A next step in the development could consist of taking the discrete support of the sleepers into account. It should be investigated if the solution techniques in $[9,13,14,25]$ can be simplified when using the current results.

\section{References}

1. Timoshenko, S.: Stresses in rails (in Russian). Trans Inst Ways of Commun (1915)

2. Timoshenko, S.; Langer, F.B.: Stresses in railroad tracks. J Appl Mech 54 (1932) 277-302

3. Hovey, B.K.: Beitrag zur Dynamik des geraden Eisenbahngleises. Dissertation, Göttingen, 1932

4. Dörr, J.: Der unendliche, federnd gebettete Balken unter dem Einfluss einer gleichförmig bewegten Last. Ing-Arch 14 (1943) 167-182

5. Dörr, J.: Das Schwingungsverhalten eines federnd gebetteten, unendlich langen Balkens. Ing-Arch 16 (1948) 287-298

6. Popp, K.; Kruse, H.; Kaiser, I.: Vehicle-track dynamics in the mid-frequency range. Vehicle Syst Dyn 31 (1999) 423-464

7. Popp, K.; Schiehlen, W.: Fahrzeugdynamik. Stuttgart: B.G. Teubner 1993

8. Kortüm, W.; Lugner, P.: Systemdynamik und Regelung von Fahrzeugen. Einführung und Beispiele. Berlin: Springer-Verlag 1994

9. Kisilowski, J.; Sowiǹski, B.: Problems of simulating vehicle motion by mathematical models. In: Kisilowski, J.; Knothe, K. (eds) Advanced Railway Vehicle System Dynamics. Warsaw: Wydawnictwa Naukowo-Techniczne 1991

10. Dukkipati, R.V.; Amyot, J.R.: Computer-aided Simulation in Railway Dynamics. New York: Marcel Dekker, Inc. 1988

11. Garg, V.K.; Dukkipati, R.V.: Dynamics of Railway Vehicle Systems. Toronto: Academic Press 1984

12. Ripke, B.; Knothe, K.: Die unendlich lange Schiene auf diskreten Schwellen bei harmonischer Einzellasterregung. Fortschritt-Berichte VDI Reihe 11 Nr. 155. Düsseldorf: VDI-Verlag 1991 
13. Sibaei, Z.: Vertikale Gleisdynamik beim Abrollen eines Radsatzes - Behandlung im Frequenzbereich. Dissertation, Fortschritt-Berichte VDI Reihe 11 Nr. 165. Düsseldorf: VDI-Verlag 1992

14. Müller, S.: Response of periodically supported tracks to moving railway vehicles - a generalization of Jezequel's solution. Z Angew Math Mech 76 (1996) Supplement 4, 157-160

15. Jezequel, L.: Response of periodic systems to a moving load. J Appl Mech 48 (1981) 613-618

16. Grassie, S.L., Gregory, R.W., Harrison, D., Johnson, K.L.: The dynamic response of railway track to high frequency vertical excitation. J Mech Eng Sci 24 (1982) 77-90

17. Ripke, B.: Hochfrequente Gleismodellierung und Simulation der Fahrzeug-Gleis-Dynamik unter Verwendung einer nichtlinearen Kontaktmechanik. Dissertation, Fortschritt-Berichte VDI Reihe $12 \mathrm{Nr}$. 249. Düsseldorf: VDI-Verlag 1995

18. Ilias, H.: Non-linear vehicle-track interaction in consideration of vertical and lateral dynamics. $\mathrm{Z}$ Angew Math Mech 76 (1996) Supplement 4, 141-144

19. Nielsen, J.C.O.; Igeland, A.: Vertical dynamic interaction between train and track - influence of wheel and track imperfections. J Sound Vib 187 (1995) 825-839

20. Igeland, A.: Time domain solution of the dynamic interaction between railroad structures and moving loads. Z Angew Math Mech 76 (1996) Supplement 4, 137-140

21. Coussy, O.; Said, M.; van Hoove, J.-P.: The influence of random surface irregularities on the dynamic response of bridges under suspended moving loads. J Sound Vib 130 (1989) 313-320

22. Lutzenberger, S.; Dinkel, J.; Baumgärtner, W.: PRISIM - Ein Softwaremodul zur Simulation der dynamischen Interaktion zweier relativ zueinander bewegter Finite Element Strukturen. DeutschSprachige MSC - NASTRAN Anwenderkonferenz, Kloster Andechs, 1998 (Proceedings unpublished)

23. Frýba, L.: Vibration of Solids and Structures Under Moving Loads. Groningen: Nordhoff International Publishing 1972

24. Frýba, L.: Dynamics of Railway Bridges. London: Thomas Telford 1996

25. Ilias, H.; Knothe, K.: Ein diskret kontinuierliches Gleismodell unter Einfluß schnell bewegter, harmonisch schwankender Wanderlasten. Fortschritt-Berichte VDI Reihe 12 Nr. 171. Düsseldorf: VDIVerlag 1992

26. Liedl, U.: Gekoppelte elastisch gebettete Balken unter bewegter harmonischer Belastung. Diploma thesis, Lehrstuhl für Baumechanik, TU München 1998

27. Bitzenbauer, J.: Vertikale dynamische Interaktion zwischen Fahrzeug und Oberbau. Diploma thesis, Lehrstuhl für Baumechanik, TU München 1999

28. Knothe, K.; Wu, Y.: Receptance behaviour of railway track and subgrade. Arch Appl Mech 68 (1998) 457-470

29. Dinkel, J.; Grundmann, H.: Winkler parameters for railway dynamics derived from 3-D half-space analysis. In: Frýba, L.; Náprstek, J. (eds.) Structural Dynamics, Proc. of EURODYN '99, pp. 831-836. Rotterdam, Brookfield: A.A. Balkema 1999

30. Dinkel, J.: Ein semi-analytisches Modell zur dynamischen Berechnung des gekoppelten Systems Fahrzeug-Fahrweg-Untergrund für das Oberbausystem Feste Fahrbahn. PhD Thesis, Lehrstuhl für Baumechanik, TU München 2000

31. Dieterman, H.A.; Metrikine, A.: The equivalent stiffness of a half-space interacting with a beam. Critical velocities of a moving load along the beam. Eur J Mech A/Solids 15 (1996) 67-90 